Published in final edited form as:

Curr Psychiatry Rep. 2017 June ; 19(6): 34. doi:10.1007/s11920-017-0782-x.

\title{
Sleep in Children with Autism Spectrum Disorder
}

\author{
Margaret C. Souders ${ }^{1}$, Stefanie Zavodny ${ }^{1}$, Whitney Eriksen ${ }^{1}$, Rebecca Sinko ${ }^{2}$, James \\ Connell $^{3}$, Connor Kerns ${ }^{3}$, Roseann Schaaf ${ }^{2}$, and Jennifer Pinto-Martin ${ }^{1}$ \\ ${ }^{1}$ University of Pennsylvania School of Nursing, 418 Curie Blvd, Philadelphia, PA 19104, USA \\ ${ }^{2}$ Thomas Jefferson University, 130 S. 9th St, Philadelphia, PA 19107, USA \\ ${ }^{3}$ AJ Drexel Autism Institute, 3020 Market St \#560, Philadelphia, PA 19104, USA
}

\begin{abstract}
The purposes of this paper are to provide an overview of the state of the science of sleep in children with autism spectrum disorder (ASD), present hypotheses for the high prevalence of insomnia in children with ASD, and present a practice pathway for promoting optimal sleep. Approximately two thirds of children with ASD have chronic insomnia, and to date, the strongest evidence on promoting sleep is for sleep education, environmental changes, behavioral interventions, and exogenous melatonin. The Sleep Committee of the Autism Treatment Network (ATN) developed a practice pathway, based on expert consensus, to capture best practices for screening, identification, and treatment for sleep problems in ASD in 2012. An exemplar case is presented to integrate key constructs of the practice pathway and address arousal and sensory dysregulation in a child with ASD and anxiety disorder. This paper concludes with next steps for dissemination of the practice pathway and future directions for research of sleep problems in ASD.
\end{abstract}

\section{Keywords}

Autism spectrum disorder; Sleep; Insomnia; Hyperarousal; Behavioral intervention; Biological rhythms

\section{Introduction}

Sleep is critical for typical synaptic development and brain maturation, and poor sleep can have detrimental effects on childrens' cognition in the domains of attention, memory, mood regulation, and behavior $[1-4,5 \bullet]$. Great concern has been voiced about the high prevalence of poor sleep in children worldwide, and the effects of poor sleep may be even more pronounced in children with neurodevelopmental disorders, including autism spectrum

Correspondence to: Margaret C. Souders.

Conflict of Interest: Margaret C. Souders, Stefanie Zavodny, Whitney Eriksen, Rebecca Sinko, James Connell, Connor Kerns, Roseann Schaaf, and Jennifer Pinto-Martin report that the case presented in this review manuscript was a participant in a study funded by a grant from the Department of Defense.

Compliance with Ethical Standards: Human and Animal Rights and Informed Consent: The case presented in the article was part of a research study funded by the Department of Defense and approved by the IRB at the Children's Hospital of Philadelphia (IRB 13-010092). Informed consent from the parents and assent from the child were obtained. 
disorder (ASD) [5•, 6, 7]. Children with ASD often have difficulties with falling and staying asleep, with night wakings having a strong association with daytime behavior problems [5•].

ASD is a complex neurodevelopmental disorder that has seen a marked increase in the prevalence over the past 30 years with a current rate of 1 in 68 children in the United States (US) [8]. One in 42 boys and one in 189 girls are identified as having ASD, a 4.5:1 ratio [8]. ASD is thought to be a multi-genetic disorder with high heritability, and autism risk may be sexually dimorphic with most genetic studies consistent with a female protective effect [912]. The recurrence risk in families ranges from 10 to $25 \%$ with a birth interval of less than 18 months increasing risk $[13,14]$. Substantial heterogeneity exists in the degree of intellectual ability, social and communication impairments, and collection of behavioral symptoms. Cognitive ability varies with $31 \%$ of individuals with ASD having IQ scores in the range of intellectual disability (IQ 570 ), 23\% in the borderline range (IQ = 71-85), and $46 \%$ in the average or above average range of intellectual ability (IQ > 85) [8]. ASD is a lifelong disorder that has major implications for the quality of life of the individual with ASD as well as the families, resulting in a tremendous responsibility on the part of the public health and education systems $[15,16]$.

Leo Kanner first described children with significant impairments in social interaction, restricted and repetitive behaviors, and often unusual sensory responses to environmental stimuli as having autism [17, 18]. Advances in our understanding of the etiology of autism have been modest over the past 73 years, but over the last two decades, there has been considerable progress in conceptualizing autism as a spectrum disorder and delineating the variability in the phenotype. In the 1990s, clinicians and researchers achieved consensus on the core deficits central to its definition and established an agreement between the two major diagnostic systems, the 4th edition of the American Psychiatric Association (APA)

Diagnostic and Statistical Manual of Mental Disorders (DSM-IV) and the 10th edition of the World Health Organization (WHO) International Classification of Diseases [4, 19]. The consensus on the core deficits for autism facilitated the development of two widely accepted, internationally recognized clinical diagnostic tools, the Autism Diagnostic Observation Schedule (ADOS) and the Autism Diagnostic Interview (ADI) [20].

Autism is currently conceptualized as a spectrum with the DSM-V (2013) merging the previous categories of Pervasive Developmental Disorders of Autism, Pervasive Developmental Disorder-Not Otherwise Specified (PDD-NOS), and Asperger Disorder from the DSM-IV into one diagnostic category of Autism Spectrum Disorder [21]. The current diagnostic criteria for ASD in the DSM-V describe two groups of characteristics: (1) persistent deficits in social communication and social interactions across contexts and (2) restricted, repetitive patterns of behavior and unusual responses to sensory stimuli [21]. The refinement of the DSM criteria along with the development and dissemination of diagnostic tools has (1) generated very skilled ASD providers; (2) encouraged local, state, and national policy development on screening, diagnosis, and treatment of ASD; and (3) stimulated greater public awareness. Taken together, these accomplishments and possible environmental, genetic, and epigenetic phenomena have contributed to the increasing prevalence of ASD worldwide. 


\section{What Is Insomnia and What Is the Prevalence of Insomnia in Children with ASD?}

Insomnia in children is defined as sleep onset delay (sleep latency) more than 30 min per night, on average, and/or frequent prolonged night waking with impaired daytime functioning [22]. Prolonged night waking alters sleep efficiency which is defined as the ratio of total sleep time in the episode potentially filled by sleep (time asleep / [total time in bedtime to fall asleep]). A sleep efficiency of $85 \%$ or greater is considered good sleep [22]. Insomnia in children with ASD occurs across all cognitive levels, and the prevalence may be as high as $60-86 \%$, which is two to three times greater than typically developing (TD) children [3, 7, 22-27]. Insomnia in children with ASD is one of the primary concerns parents have and one of the major reasons why many families seek medical help [28]. Moreover, insomnia in children with ASD has been found to alter parents' sleep and add tremendous stress to their families' lives [29]. A recent meta-analysis of sleep data in children with ASD showed small but measurable differences in sleep parameters using objective measures of actigraphy (ACT) and/or polysomnography (PSG) [30]. ACT is a miniaturized wristwatch-like microcomputer that senses physical motion and generates a signal each time it is moved (accelerated) and generally placed on the wrist. The stored movement data can be transferred to a computer for interpretation and estimation of sleep parameters. Studies utilizing ACT and PSG with children with ASD have found shorter sleep time, longer sleep latency, and decreased sleep efficiency as compared to TD control groups [30].

\section{What Are the Hypotheses for the High Prevalence of Insomnia in Children with ASD?}

Sleep problems in ASD have many possible neurobiological, medical, behavioral, and cultural mechanisms, and the cause in any given child is likely to be multi-factorial [22, 31, $32,24,26]$. Behavioral insomnias of childhood (BIC) are the most common extrinsic causes of insomnia in children, including those with ASD [26, 32-34]. However, the underlying biological and behavioral rhythms of ASD may predispose children to both extrinsic and intrinsic stressors that threaten sleep, making children with ASD uniquely vulnerable to sleep problems [11, 26, 31, 35]. Hypotheses regarding intrinsic causes of insomnia in children with ASD include (1) brain wave organizational and maturational differences, (2) circadian-relevant genes, (3) abnormal melatonin production, and (4) arousal and sensory dysregulation. Intrinsic hypotheses for insomnia will be presented first and followed by extrinsic causes of insomnia in children with ASD.

\section{Brain Wave Organization and Maturation Differences}

The first hypothesis regarding an intrinsic cause of insomnia involves possible differences in brain wave organization and maturation identified by polysomnography (PSG). PSG, the collective process of monitoring and recording physiologic data during sleep, is considered the gold standard for objective measurement. It can include, but is not limited to, electroencephalographic activity (EEG), electro-oculogram, electromyography activity, rhythm electrocardiogram, airflow via nasal pressure thermistor or pneumotachograph, and 
oxygen saturation via pulse oximetry [36]. PSG frequency bands of $12-15 \mathrm{c} / \mathrm{s}$ activity during REM have been described as occurring in premature infants and infants ages 3-8 months. An early PSG study from 1969 with children with ASD ages 19-47 months revealed frequency bands of 10.5-15 c/s activity during rapid eye movement (REM) as compared to an almost complete absence in same age controls with typical development, suggesting a maturational difference in children with ASD [37]. Moreover, they also found an association between slow wave activity and REM burst activity during REM in typically developing children, but this association was not observed in children with ASD, suggesting an immature organizational pattern. In 1976, Tanguay and colleagues built upon previous work and noted that eye movements (EMs) do not become organized into bursts until approximately 40-weeks gestation [38]. In their study, they found that the mean eye movement burst length and the ratio of EMs within bursts to EMs outside of bursts was significantly less in children with ASD as compared to age-matched controls, emphasizing the immaturity of eye movement organization in children with ASD [38]. In addition, spindle EEG activity was found during REM in children with ASD but not in same age controls, suggesting that sleep stages were not well differentiated [38]. Theories regarding brain organization and maturation were not studied again until the 1990s, when four other studies reported higher rates of undifferentiated sleep, muscle twitching during REM sleep, high rates of periodic limb movement syndrome (PLMS), and REM sleep behavior disorder as compared to typically developing controls [39-42].

In 2006, 21 children with ASD were compared to 10 TD controls utilizing two nights of PSG and a sleep questionnaire [43]. The ASD cohort was divided into two groups, "good sleepers" and "poor sleepers," as reported by their parents. The results showed that there were no significant differences between the ASD good sleepers and TD controls on the sleep questionnaire domains or sleep architecture. However, poor sleepers with ASD showed prolonged sleep latency and decreased sleep efficiency on the first night of PSG and increased scores on the insomnia domains of the questionnaire. Interestingly, there were no significant differences between the 2nd night of PSG for the poor ASD sleepers $(n=11)$ and TD controls $(n=10)$. More recently, in 2010, a study completed in the Clinical Research Center of the National Institute of Health compared 50 children with ASD, mean age of 4.8 years with age matched controls (15 TD children and 13 children with developmental delay) [44]. The results showed statistically significant shorter total sleep time, greater slow wave sleep percentage, and much lower REM sleep percentage. The authors concluded that a deficiency of REM may indicate an abnormality in neural maturation and organization in young children with ASD and is consistent with findings from the 1960-1970s.

Despite multiple methodological limitations of these studies, the accumulated findings are considerable. These studies highlight the possibility of central nervous systems maturational and organizational differences. In addition, higher rates of parasomnias are found in children with ASD as compared to typical developing controls including abnormal frequencies of muscle twitches, muscle activity during REM, and PLMS observed during PSG. These findings may implicate dysfunction in the excitatory monoaminergic pathways and other core neurotransmitters, synaptic homeostasis involved in sleep-wake control, and perhaps phylogenetic shifts in the neuronal development of the human brain and autonomic nervous 
system. In total, these findings support the hypothesis of complex intrinsic neurobiological differences that alter sleep behaviors and sleep quality in children with ASD.

\section{Circadian-Relevant Genes}

Another emerging hypothesis for intrinsic causes of insomnia in children with ASD includes circadian-relevant gene anomalies resulting in biological and behavioral rhythm disturbances $[45,46,31,11,47,48]$. In humans, sleep and wakefulness are regulated in part by an endogenous circadian clock, the suprachiasmatic nucleus in the brain [11]. This master clock orchestrates a circadian rhythm system of positive and negative feedback loops that alter clock gene expression [11]. Clock genes PERIOD (PER 1, 2, 3 main framework), TIMELESS (resets clock), NPAS2, and Cryptocromes (CRY1,2) interact and are activated by clock proteins CLOCK, ARNTL/BMAL1 [49-52]. In 2002, clock/clock-related gene anomalies were first suggested as possible contributory factors in the etiology of core deficits of ASD involving temporary synchrony and social timing deficits [45]. Results from genetic linkage studies from multiplex families implicated chromosome $2 \mathrm{q}$ as a possible site, and region 2q37.3 has been found to have the hPER2 gene [45]. More recently, hPER2 was identified as one of the candidate genes for $2 \mathrm{q} 37$ deletion syndrome in humans resulting in the phenotype of ASD, dysmorphic features, and sleep problems [53]. In addition, two clock gene variants, in PER1 and NPAS2, were found to be associated with a 110-member autism cohort from Autism Genetic Resources Exchange [54]. The coding regions of 18 canonical clock genes and clock controlled genes were sequenced in 28 participants with ASD, and PER2, PER 3, and TIMELESS variants were found to be associated with ASD [11]. However, the results from these studies were limited by small sample sizes and/or lack of significance after corrections for multiple analyses. Still, the identification of rare mutations in clock genes with functional alterations in ASD participants suggests that further investigation with large sample sizes and deep phenotyping is warranted. Some researchers suggest the possibility that clock genes such as hPER1, hPER2, hPER3, and clock genegene interactions may serve a dual role with respect to sleep and the control of oscillators associated with human social communication and concurrent brain development [45]. Wimpory and colleagues hypothesized that variances in clock genes that orchestrate oscillator systems may underscore the social deficits of ASD [45].

Pleiotropic effects connecting many genes involving sleep and brain disorders are emerging. For example, through analysis of de novo mutations in ASD, Sanders and colleagues identified 6 loci and 65 genes associated with ASD by combining CNV and sequencing data. The NRXN1 and SHANK3 genes appear in both lists. There is a strong body of evidence indicating that $S H A N K 3$, which encodes a post-synaptic scaffolding protein, influences the combined phenotype of autism spectrum disorder symptoms with sleep disturbances and intellectual disability. Recently Veatch and colleagues have hypothesized that genes involved in synaptic homeostasis, including the processes of synaptic development and pruning, may be involved in both ASD and sleep-wake control, offering a promising shared mechanism [55•]. Investigators suggest that a greater understanding of the pleiotropic roles of genes influencing both sleep and neurological disorders could lead to new treatment strategies for children with ASD [55•]. 


\section{Abnormal Melatonin Rhythms, Peaks, and Receptor Sites}

Abnormal melatonin levels have been hypothesized to play a role in insomnia in children with ASD. Melatonin is synthesized in the pineal gland and is received in the suprachiasmatic nucleus, the master clock in the brain, by receptors MTNR1A and MTNR1B, which are involved with multiple functions including sleep induction, circadian and seasonal rhythm regulation, and immune function [11]. A delayed melatonin rhythm has been hypothesized to be associated with prolonged sleep latency, and low melatonin amplitude has been associated with night waking in children with ASD [31]. Multiple investigators have identified lower levels of melatonin or a major metabolite of melatonin (urinary 6 sulfatoxymelatonin) in either the urine, serum, or plasma of individuals with ASD $[31,46,56-60]$.

It is also hypothesized that low melatonin levels and sleep onset delay in children with ASD may be related to mutations in melatonin synthesis pathway genes or changes to regulatory regions of melatonin receptor sites [59, 61-63]. Arecent study evaluated variation in two melatonin pathway genes, acetylserotonin O-methyltransferase (ASMT) and cytochrome P450 1A2 (CYP1A2) and observed higher frequencies of variants than were currently reported in individuals with ASD [61]. Moreover, two studies investigated regulatory regions of melatonin receptors MTNR1A and MTNR1B in individuals with ASD and detected base changes in upstream regulatory regions of these receptors, suggesting that these genes were interesting candidates for ASD [62, 63]. However, one of these studies found base changes in the regulatory regions in both the ASD participants and controls. On the other hand, both studies detected p.V124I mutation in ASD participants only [62, 63]. Taken together, a combination of abnormal production, increased breakdown, and abnormal receptor sites of melatonin may explain prolonged sleep latency and night wakings in children with ASD. However, these studies were limited by small sample sizes, indicating a need for further study with larger samples [61-63].

To date, 16 treatment studies showed strong support for the effectiveness of short-term use of exogenous melatonin, dose range $0.5-15 \mathrm{mg}$, with most studies using a $3-5 \mathrm{mg}$ dose 30 min prior to desired sleep onset, to improve sleep in children with ASD [47, 64-79]. This body of evidence supports the use of melatonin and extended release melatonin in children with ASD after environmental and behavioral strategies have been implemented and are insufficient in improving sleep. However, some children with ASD do not respond to melatonin and some families find that melatonin loses its effectiveness over time [26, 72]. In addition, a recent study by Goldman and colleagues (2014) found no differences in endogenous melatonin samples comparing children with ASD and insomnia $(n=9)$ and typically developing children in maximal melatonin concentration $(\mathrm{C}(\max ))$ and time to peak concentration $(\mathrm{T}(\max ))$ [80]. These outcomes suggest that other hypotheses and opportunities for intervention regarding insomnia in children with ASD should be explored.

\section{Arousal and Sensory Dysregulation in Insomnia}

Current thinking on insomnia in the general population regards the disorder as one of hyperarousal. Early work hypothesized that insomnia was an internalization of emotional arousal [81-85] and recent research has focused on two lines of inquiry: cognitive arousal and 
increased somatic/physiological arousal. The theory of cognitive arousal hypothesizes that increased cognitive activity (thinking and worrying while trying to fall asleep) prevents the initiation of the sleep process $[82,84,85]$. The theory of physiological arousal posits that there is greater activation of the sympathetic nervous system in patients with insomnia compared to good sleepers [86]. A few small studies have characterized biomarkers of autonomic outflow and revealed that increased heart rate, body temperature, heart rate variability, and higher levels of nor-epinephrine have been correlated with insomnia $[81,86$, 87].

\section{Hyper-Arousal and Insomnia in ASD}

Since the earliest descriptions of ASD, it has been suggested that individuals with ASD may have difficulties with basic neurophysiological processes of attention and arousal. Children with ASD have been described by clinicians and therapists as being either "hypo" or "hyper" aroused to internal and external stimuli. Arousal theories remain at the heart of clinician dialog. Hutt and colleagues in 1964 were the first to hypothesize that autism involved chronically high arousal levels [88]. Dawson and Lewey (1988) described a general overarousal and narrow range of optimal arousal in autism [89]. Recent advancements in the field of neuroscience and the understanding of neural circuits have renewed interest in the arousal theories of ASD. There is growing evidence that ASD is associated with arousal dysregulation and dysregulation of the autonomic nervous system (ANS).

While insomnia in children with ASD is predominantly identified as behavioral insomnia of childhood (BIC), which is thought to be caused by external factors such as limit setting and sleep association, some studies have identified that children's anxiety, fears, worries, and sensitivities to environmental stimuli might be contributing to their insomnia [26, 24]. In our previous work, we collected data from 97 families that included a comprehensive sleep history, environmental assessment, sleep questionnaires, and ten nights of actigraphy for each child. We hypothesize that the "hyper-aroused state" experienced by a subgroup of children with ASD may be linked to insomnia [26]. We concluded that in order to develop more precisely targeted sleep treatments for children with ASD, arousal dysregulation would need to be specifically addressed. The ANS is divided into three divisions: sympathetic, parasympathetic, and enteric branches. ANS hyper-arousal may be related to sympathetic hyper-arousal, parasympathetic undertone, or atypical interaction of the two systems. A few small studies evaluated sensory arousal and sympathetic tone using electrodermal activity (EDA) in children with ASD compared to controls, and the results are inconsistent. Two studies observed larger tonic EDA in response to sounds [90,91] while two other studies found no changes in response to auditory stimuli $[92,93]$. However, Ming and colleagues (2005) investigated autonomic dysfunction using a Neuroscope, a device that measures brainstem activity and quantifies cardiac vagal tone, blood pressure, and heart rate in realtime and found that all children with ASD had elevated sympathetic tone compared to TD children [94].

\section{Sensory Hyper-Reactivity and Insomnia}

Hyper-arousal can also be described by occupational therapy scientists as sensory hyperreactivity Sensory hyper-reactivity may be one factor related to insomnia in children with 
ASD. Reynolds, Lane, and Thacker (2012) showed that children with ASD ages 6-12 had a greater prevalence of atypical sensory behaviors and sleep disturbances than typically developing children as measured by the Short Sensory Profile [95, 96]. Moreover, a sensory challenge protocol predicted good versus poor sleepers with $87 \%$ accuracy [97]. Specifically, behaviors associated with avoiding sensation on the sensory profile [98] were highly correlated with sleep problems in the children with ASD. Sensory avoiding behaviors include avoiding playground equipment or moving toys, avoiding going barefoot in sand or grass, and avoiding certain tastes or foods that are typically part of the child's diet [98]. In Dunn's model of sensory processing, sensory avoiding is hypothesized to be related to low sensory thresholds and resultant sensory hyper-reactivity. Thus, this finding suggests that children with ASD may over-react to stimuli resulting in difficulty falling or staying asleep. Similarly, Mazurek and Petroski (2015) used data from the Autism Treatment Network and found that greater levels of sensory over-responsivity measured by the sensory profile were positively correlated with more overall sleep problems measured by the CSHQ [99•]. Hollway and colleagues (2013) conducted a correlational analysis of data from 1347 children (ages 2-17) in the Autism Treatment Network and found predictors of sleep difficulties using hierarchical regression modeling of 1583 children with ASD (ages 2-17) in the Autism Treatment Network data bank [100•]. Findings suggest that sleep difficulties are related to problems in specific sensory areas, and children with a high sensory threshold who require high levels of sensory input sleep better. Specifically the overall sleep difficulty score on the CSHQ had an inverse relationship with the Auditory Filtering and Under-responsive/ Seeks Sensation/Sensory Seeking sections of the Short Sensory Profile. Auditory filter is the ability to detect the salient features of auditory sensations, and the under-responsive/seeks sensation category is associated with high neurological thresholds for responsiveness requiring more sensory input and promoting sensory-seeking behaviors in children with ASD [98]. There is some evidence that insomnia in children with ASD may be at least partially related to poor sensory processing, and thus, assessment of sensory reactivity may be useful when addressing insomnia. Strategies to manage sensory hyper-reactivity such as decreasing environmental stimuli in the bedroom and/or adding calming strategies prior to bedtime may be appropriate.

\section{Co-occurring Psychiatric Disorders}

More recently, there has been greater attention by clinicians and researchers on recognizing co-occurring psychiatric disorders in children with ASD. A high prevalence of anxiety and/or ADHD, which are considered high arousal disorders, have been identified in multiple studies in children with ASD [101-106]. In addition, a recent study using electrodermal activity (EDA), a non-invasive physiological indicator of autonomic activity, was measured in typically developing children and children with ASD. Participants performed tasks that elicit anxiety, attention, response inhibition, and social cognition processes. The ASD group was divided into low- and high-anxiety participants, and the groups were compared to mean EDA level. The ASD group had a significantly blunted mean EDA response to the anxiety tasks. The high-anxiety ASD group showed significantly decreased mean EDA compared to both the low-anxiety ASD group and the typically developing control group. The results suggest atypical autonomic function in children with ASD, specifically with respect to 
sympathetic activity. Moreover, anxiety symptomatology defined subgroups with distinct physiological and behavioral profiles. Overall, the results add to the body of literature supporting autonomic dysfunction in ASD and highlight the role of anxiety and autonomic features in explaining the variability in the autism spectrum [107].

Taken together, the high prevalence of high arousal psychiatric disorders, unusual responses to sensory stimuli, and insomnia in children with ASD may provide a greater understanding of a cluster of symptoms that can be identified as arousal and sensory dysregulation.

\section{Norepinephrine and Prefrontal Cortex Cognitive Abilities}

One neural system that could account for both arousal and sensory dysregulation and cognitive challenges described in ASD is the locus coeruleus-norepinephrine system. Over the past 20 years, multiple studies have documented the dominant role of norepinephrine in regulating the working memory and attentional functions of the prefrontal cortex [108-110]. The pontine nucleus of the locus coeruleus is the source of a widely divergent projection system that provides the majority of all norepinephrine to the brain and is the sole source of norepinephrine in the cortex $[110,109]$. This system is activated by diverse sensory and autonomic stimuli and its activation is associated with forebrain arousal [111,112]. Electrophy siological studies in rats and non-human primates suggest that there is an inverted U-shaped relationship between the locus coeruleus, neuronal discharge, and prefrontal cortex cognitive abilities [105, 106].

This U-shaped model provides a framework for better understanding of the arousal dysregulation and "hyper" and "hypo" arousal symptoms in children with ASD. When the locus coeruleus neurons are in a phasic mode, they are very responsive to sensory stimuli which is associated with optimal performance in tasks requiring focused attention [113]. However, levels of locus coeruleus discharge and norepinephrine outside the optimal range are associated with poor performance. High levels of norepinephrine (i.e., high tonic activity) are associated with hyper-arousal and a loss of response to specific stimuli [113]. Given these characteristics of the norepinephrine system, ASD symptoms related to arousal and abnormal sensory responses could result from locus coeruleus-norepinephrine dysfunction. In addition, the wake and arousal-promoting actions of central noradrenergic neurotransmission may have clinical consequences in a number of conditions associated with the dysregulation of sleep and waking and/or arousal. For example, acute activation of LC-noradrenergic signaling is incompatible with the state of sleep [114]. As early as 1956, researchers have identified the relationship between norepinephrine and sleep/wake state [115]. Thus, inappropriate excitatory drive on this system, which can arise from upstream regions including the prefrontal cortex and amygdala, could contribute to an inability to fall or stay asleep associated with insomnia [114]. The "hyper" or over-aroused child with ASD has behavioral symptoms of inattention, impulsivity, high activity, anxiety, panic, and insomnia. 


\section{Extrinsic Causes of Insomnia in Children with ASD}

Behavioral insomnias of childhood (BIC) are the most common causes of insomnia in children with and without ASD [32, 26, 33, 34]. Sleep-onset association type is characterized by the child's dependency on a specific stimulation, person, objects, or settings for initiating sleep or returning to sleep. Limit setting type is characterized by bedtime stalling or refusal behaviors that are a result of difficulties with limit setting by the caregiver. The stalling and refusal behaviors escalate each night and can become quite disruptive. These behaviors are inadvertently reinforced by postponing bedtime and providing a child with 1:1 attention [26]. Caregivers of children with ASD often will initiate multiple ideas to help their child fall asleep and may establish bed time conditions that inadvertently perpetuate chronic insomnia [26].

The insomnia model denoted by Spielman and colleagues (Fig. 1) describes predisposing, precipitating, and perpetuating factors significant to the development and maintenance of insomnia [116]. Predisposing factors include genetic, physiological, or psychological phenomena that confer differential susceptibility to individuals [116]. Precipitating factors include physiological, environmental, or psychological stressors which push an individual over a hypothetical insomnia threshold to produce acute symptoms [116]. Perpetuating factors include behavioral, psychological, environmental, and physiological factors that prevent the individual from re-establishing normal sleep [116]. In pediatrics, health providers have often focused on behavioral conditions created by caregivers in an attempt to relieve insomnia symptoms in their children which often inadvertently worsen those symptoms and perpetuate insomnia.

Based on the Spielman model of insomnia (Fig. 1), the neurobiological and neuropsychiatric vulnerability of children with ASD represent the predisposing factors. These predisposing factors position children with ASD close to the hypothetical threshold of insomnia.

Precipitating factors including (1) environmental stresses such as changes in evening routine and sensory stimuli, (2) psychological stressors such as a difficult day at school, or (3) physiological stressors such as being sick may push a child with ASD across the threshold into insomnia. In attempting to treat the child's insomnia, parents may inadvertently introduce perpetuating factors such as getting in bed with the child until they fall asleep, or allowing the child to nap after school. For this reason, caregivers of children with ASD and insomnia often will need the support of health care providers in identifying the child and parents' specific predisposing, precipitating, and perpetuating factors.

\section{Practical Approaches to Sleep Problems in Children with ASD}

The Autism Treatment Network (ATN) recognized that it is critical for providers to be well trained in delivering sleep care to this vulnerable population. To address this need, the ATN created a Sleep Committee to compile evidence-based treatments and refine decisionmaking tools in order to produce a practice pathway and sleep tool kit. The Sleep Tool Kit (KIT) is a standardized manual for educating families on sleep hygiene and basic behavioral strategies and available to all online. This informational packet is designed to provide parents with strategies to improve sleep in their child including a visual schedule to teach 
bedtime routines, images for a visual schedule, using a bedtime pass, and sleep tips for children with limited verbal skills. Used together to support practitioners and families, the pathway and sleep tool kit are the standard of care for identifying, evaluating, and managing insomnia in children and adolescents with ASD [117•].

The ATN practice pathway was devised from a thorough review of the state of the science and included 20 intervention articles studying individuals with ASD with sample sizes of 10 or greater [117•]. The pathway was based on a consensus of sleep experts that captured best practices for an overarching methodology to implementing comprehensive sleep care by primary care providers or ASD specialists. The ATN tested the pathway at 4 pilot sites across the USA. The pathway has a ten-step approach (Table 1) and includes screening for and treating medical conditions that may be related to poor sleep (Table 2) and being aware of signs and symptoms of obstructive sleep apnea and its risk factors (Table 3). A pilot phase showed that barriers to using the ATN pathway included lack of time during a clinic visit and limited provider knowledge of and comfort with both assessment and management of insomnia [117•]. Moreover, the 2014 study by Malow and colleagues implementing the ATN sleep tool kit identified that the education session improved sleep in children with ASD on average but some continued to meet criteria for insomnia, suggesting that the tool kit is not sufficient for all families and they may require more support and tailored strategies [32]. The following case study illustrates key concepts to increase provider comfort with identifying, evaluating, and managing insomnia in children and adolescents with ASD and introduces a calming module supplement.

The child in the case participated in an insomnia study titled Tailored Behavioral Intervention (TAB) for Children with ASD and Insomnia. This pilot randomized controlled trial (RCT) compared the effects of standard care plus TAB protocol to standard care only. In this study, standard care was defined as the ATN sleep tool kit, a 1-h education session with emphasis on ecological approach and establishing positive evening routines. The TAB, a home-based weekly intervention delivered by nurses or occupational therapists using performance feedback, included three components (1) positive evening routines with visual schedule, (2) supplemental calming module (developed by the authors to decrease arousal levels), and (3) a faded bedtime protocol that has a child go to bed when they are irresistibly sleepy, equating sleepiness with their bedroom (stimulus control). The environmental changes, bedtime routines, and calming activities were tailored to each child and family, based on their arousal (anxiety and sensory sensitivities) profile, sleep characteristics, and the family's identified goals.

The supplementary calming module was developed based on the idea that a subgroup of children with ASD are in a hyper-aroused state and may have anxiety and sensory dysregulation, and it includes a list of evidence-based calming activities [32]. The calming module activities address the internal factors including sensory and arousal dysregulation that threaten sleep. The goal was to address the child's sensory needs and arousal levels by altering the environment and tailoring specific calming module activities to target the child's arousal profile. The calming module includes 12 individualized soothing and relaxing activities that are selected by the parents/child and providers based on their arousal profile. The calming activities included the following: (1) breathing techniques [118]; (2) muscle 
relaxation techniques [118]; (3) yoga poses [119]; (4) massage [120-123]; (5) mindfulness exercises [124]; (6) worry box/doll [125]; (7) emotional regulation: positive emotions; (8) taking a warm bath; (9) gentle rocking; (10) gentle swinging; (11) self-soothing: soothing the five senses [118]; and (12) quiet activities: reading, prayers. These activities have been found to be successful in calming individuals with arousal/anxiety symptoms.

\section{Identifying Information and Presenting Concerns}

Tim (alias) is an 8-year-old Caucasian male who is diagnosed with ASD, generalized anxiety disorder, and oppositional defiant disorder. He had a history of developmental delays and difficulties with social interaction. He lives with his mother and father in a suburban single family home and he has his own bedroom. Both parents have bachelor degree level of education and his mother is a nurse and his father is a respiratory therapist. Tim has an older brother age 11 with typical development. Tim attends third grade in a public school and is in a regular education classroom. He has full scale IQ of 110 and does well academically. Parents reported that Tim did not want to sleep in his own room and he slept in his brother's room in a twin bed. His brother slept in the other twin bed, and both beds were up against the walls. He refused to sleep by himself and demanded that his mother sleep with him each night. There was a ceiling fan, two windows, two dressers with lamps, and a toy chest. He had difficulties falling asleep and often woke during the night, and the mother reports he was a very restless sleeper with frequent movement.

\section{Children's Sleep Habits Questionnaire}

The Children's Sleep Habit's Questionnaire (CSHQ) was chosen because it is a comprehensive instrument to screen for both behavioral and physiological disorders of sleep. The CSHQ is a structured parent-report sleep screening instrument designed for school-aged children. Parents respond to items on a 3-point Likert scale (rarely $=0-1$ night per week; sometimes $=2-4$ nights per week; usually $=5-7$ nights per week). The CSHQ has both a total score (48 items) and eight subscale scores (33 items), reflecting key sleep domains that encompass the major medical and behavioral sleep disorders in this age group, with higher scores reflecting greater problems, in bedtime resistance, sleep onset delay, sleep anxiety, night wakings, parasomnias, sleep disordered breathing, and daytime sleepiness. The CSHQ individual items, as well as the subscale and total scores, were able to consistently differentiate the community group from the sleep-disordered group, demonstrating validity. A cut-off total score of 41 generated by analysis of the receiver operator characteristic (ROC) curve correctly yielded a sensitivity of 0.80 and a specificity of 0.72 [126].

Tim had a total score of 57 which was above the cut-off of 41 and had elevated subscales for bedtime resistance, sleep duration, sleep anxiety, and night wakings consistent with a sleep disordered group (Table 4). The elevated sleep anxiety and bedtime resistance subscale scores indicate a need to focus on decreasing anxiety before bed and developing a nighttime routine with behavioral reinforcements for completing the routine. 


\section{Anxiety Interview and Questionnaire}

Anxiety was assessed via a clinician-administered semi-structured interview with the parent, the Pediatric Anxiety Rating Scale (PARS; [127], and a parent-report questionnaire about child anxiety symptoms, the Screen for Anxiety and Related Emotional Disorders (SCARED). The PARS is a semi-structured interview designed to assess the presence and severity of a range of pediatric anxiety symptoms, such as symptoms of panic, specific phobias, and also generalized separation and social anxiety in children. It provides a continuous rating of the cumulative impairment of these symptoms, including impairments in peer, academic, and family functioning and physical health. A 5-item total score of 11.5 or greater on the PARS suggests significant risk for anxiety disorder. The PARS has demonstrated inter-rater reliability (.86), high test-retest reliability (.83), and convergent validity in anxious youth with ASD $[128,129]$ and has shown sensitivity to treatment effects in clinical trials of anxiety interventions for children with ASD [130, 131]. For this study, the PARS was administered by C.K. who has received standard training and demonstrated research reliability in this measure. In addition, Tim's mother completed the SCARED, a 41item parent-report questionnaire that assesses symptoms of panic/somatic anxiety, separation anxiety, social anxiety, school refusal, and generalized anxiety. Like the PARS, the SCARED has good psychometric properties in large clinical samples [132, 133] and sensitivity to treatment effects in children with ASD [134]. Given that brief parent questionnaires have been found to have reduced sensitivity and specificity for detecting anxiety in children with ASD [102], the SCARED was combined with the PARS to provide a more comprehensive assessment of Tim's anxiety profile.

Results of the clinician-rated PARS indicated that Tim showed clinically significant symptoms of anxiety (PARS 5-item total $=14,>11.5$ cut-off) at pretreatment directly related to his sleeping habits and routine. Tim struggled to sleep in his bed at night and to sleep away from home due to preoccupying worries and anxiety about the dark and about being separated from his parents. These fears resulted in significant interference to Tim and his family's daily routines. Tim struggled to go to sleep at night in his own bed, preferring to sleep with his mother due to his separation anxiety. His fears of the dark also contributed to nightly agitation, fretfulness, and worry that made it difficult to fall asleep. In addition, he expressed fears of thunderstorms and lightening causing power outages and inescapable darkness. Symptoms of separation anxiety and physical anxiety symptoms were also apparent on the SCARED (total score = 23); however, they did not exceed the SCARED cutoff for clinically significant anxiety.

\section{Sensory Information}

Sensory characteristics were evaluated using the sensory profile. The sensory profile [98] is a parent questionnaire that measures children's responses to sensory events in daily life and provides data about how patterns of sensory-related behaviors might be contributing to, or creating barriers for, performance in daily life [98]. The sensory profile yields numerical scores for each area (e.g., touch processing), and these are rated as typical, probable difference, or definite difference based on normative data. The sensory profile has good construct validity, strong internal reliability (>.80), and discriminate validity (>95\%) in identifying children with and without sensory issues [98]. On the items assessing specific 
sensory system processing, Tim scored in the definite difference range in auditory and oral sensitivity, movement seeking behaviors, and processing of multisensory stimuli (Table 5). He showed some difficulty (probable difference) in the areas of visual discrimination, sensory processing related to endurance and tone, and tactile seeking behaviors. This sensory profile suggests that Tim could benefit from a simple visual schedule, a peaceful environment, and calming activities that address his movement and tactile seeking behaviors.

\section{Baseline Actigraphy}

As shown in Table 4 and Fig. 2, at baseline, Tim slept an average of $375.63 \mathrm{~min}(6 \mathrm{~h}$ and 26 $\mathrm{min}$ ) and average awake time was $205 \mathrm{~min}$ ( $3 \mathrm{~h}, 40 \mathrm{~min}$ ). His sleep latency (time to fall asleep) averaged $37.75 \mathrm{~min}$, which falls in the range of insomnia. Sleep efficiency was scored as 74.3 .

\section{The Intervention}

During the initial home visit, questionnaire and actigraphy data were reviewed with parents and the child and the child's sleep environment was assessed. The family received a 1-h ATN education session that was tailored to their specific needs and incorporated positive evening routines, ecological changes to bedroom and with visual schedule with laminated icons on Velcro board from the sleep tool kit (Table 6).

\section{Positive Evening Routines with Visual Schedule}

During the initial home visit, the team (nurse and occupational therapist) and family collaborated to establish a bedtime routine, create a visual schedule showing the sequence of the bedtime routine, and decide on environmental changes. These changes included decreasing the amount of toys and removing the TV from Tim's bedroom to decrease extraneous stimuli. The team also educated the family on the importance of creating a cool, dark environment to facilitate sleep, including keeping the temperature lower at night. Given that this child currently slept with his mother and brother, the family and the team felt it was important to transition to his own bedroom.

To facilitate this transition, they suggested a red nightlight in his room and a body pillow wrapped in his mother's pajamas and sprayed with her favorite perfume. This latter strategy served as a comfort item for the child and was based on his olfactory seeking behaviors via the sensory profile. To foster the transition from his brother's room to his own bedroom, everyone including Tim agreed that the mother or father would sit in a chair next to him until he fell asleep. The chair was slowly moved closer to the bedroom door each night.

Additionally, the use of a bedtime pass was implemented in which Tim was provided with a laminated bedtime pass at bedtime. The protocol was if he wakes during the night and needs to get his parents for a hug or reassurance, he would need to give up the bedtime pass. They would offer brief comfort and then they put in back to bed in his own room. If Tim was able to stay in his room through the night and woke up with the bedtime pass, he earned a reward that morning. Tim chose an action figure. It was recommended to initially begin with two passes to increase likelihood of success for this child. 


\section{Supplemental Calming Module and Activities}

Calming activities were included as part of the bedtime routine. Based on the child's sensory needs, anxiety, interests, and preferences, specific calming activities were selected. The chosen strategies included a massage, and a vanilla-scented candle was lit during the massage. These activities were selected because the child's sensory profile indicated that olfaction may be a useful sensation for calming and that he enjoyed deep pressure tactile input; Yoga poses were also selected (legs on wall, sleeping pose) to build on the child's proprioceptive needs. Observing your breath or deep breathing was also selected for the child to perform during yoga poses to assist with relaxing his body. In addition, the family was encouraged to incorporate at least $20 \mathrm{~min}$ of exercise into the daily routine. This included use of the family's exercise bike, wheelbarrow walking, pushups, and army crawl. This addressed the child's movement seeking behaviors by providing increased activity and body movement against resistance.

\section{Faded Bedtime Protocol}

A faded bedtime routine was established with the family to ensure that the child was sleepy when he went to bed. The faded bedtime protocol requires the child to wait to go to bed until they are irresistibly sleepy, in order to equate sleepiness with their bedroom (stimulus control). The bedtime was pushed back from 8 to 8:45 PM, and the calming activities discussed above were added into the child's routine prior to bed to occupy the time. If Tim was successful with falling asleep at 9:00 PM for a week or two, then the bedtime could be faded back to 8:30 and adjusted by 15-min intervals to a desired bedtime.

Fidelity

During each visit, fidelity to the agreed-upon sleep routines was assessed. The fidelity checklist was created and included the prescribed intervention activities. If strategies were not used, they were discussed to determine if adaptations were needed or if the strategy could be discontinued because it was not a good fit. Fidelity of performance on the calming activities was also checked. This family consistently implemented the recommended strategies each week without difficulty. However, the child did become perseverative on the reward system created with the bedtime pass, which led to behavioral disruptions in the morning; behavioral strategies were implemented to address the morning disruptions. These were developed by the occupational therapist in consultation with a behavioral specialist. It was recommended that the parents be consistent and calm when dealing with behaviors. Additionally, a behavior chart was created and a social story was developed. Lastly, it was recommended that the family use a consistent time for rewards including completion of the child's morning routine prior to reward, use a timer to select and use the reward, and gradually fade amount and frequency of rewards.

\section{Results}

As shown in Table 4 and Fig. 2 below, parents reported a great improvement in Tim's sleep behaviors and shown with the CSHQ total score decreasing from 57 to 41 . Moreover, the objective measure of actigraphy revealed that sleep latency (time to fall asleep) decreased 
from 37.75 to $13.22 \mathrm{~min}$, and his sleep minutes improved from 375.63 to $455.4 \mathrm{~min}$, an increase of over an hour. The nighttime pass intervention was successful and Tim was staying in his own room throughout the night.

In addition, clinically significant improvements were observed in the child's anxiety symptoms, as rated by both the PARS and SCARED. Following the intervention, Tim no longer exceeded the clinical cut-off for anxiety on the PARS (post-PARS total $=10,<11.5$ cut-off). In addition, he exhibited fewer anxiety symptoms as reported by his mother on the SCARED (pretreatment SCARED total $=23$ vs post-treatment SCARED total $=15$ ). Following intervention, Tim's mother described that Tim no longer had difficulties falling asleep alone at night. In addition, she reported that his fears of the dark and storms/bad weather were much less overwhelming to him and interfering in his life. Though Tim still sometimes expressed worries about bad weather and the dark, he was no longer preoccupied or overwhelmed by these concerns, but rather could be reassured and redirected to other topics. Moreover, Tim demonstrated an ability to overcome these worries in order to stay and fall asleep in his own bed at night.

\section{Summary of Case}

Tim made measurable improvements in his sleep and anxiety as seen in Table 4. The family reported being very satisfied with the child's sleep behavior at the end of the intervention. Much of the success of this case can be attributed to the family's consistency in implementing the recommended strategies and incorporating the strategies into their daily routines so that it was not viewed as additional work. Additionally, eight home visits provided the necessary feedback to the family and served as a means to address any concerns that emerged.

\section{Conclusion}

Children with ASD are extremely vulnerable to sleep problems due to underlying biological and behavioral rhythms that predispose them to extrinsic and intrinsic stressors affecting sleep. There is growing evidence that ASD is associated with arousal dysregulation and sensory hyper-reactivity, and calming strategies may be helpful in improving sleep.

The strongest evidence to date on promoting sleep in ASD supports sleep education, ecological and behavioral interventions, and exogenous melatonin. Exciting future research direction should investigate clock genes and clock controlled genes and their relationships with ASD using big genetic data sets and deep phenotyping. Deep phenotyping that includes characterization of sleep problems, arousal and sensory dys-regulation, biomarkers, including catecholamines, heart rate variability, stress hormones, would give us a greater understanding of the causes of sleep problems in ASD and is urgently needed.

The case presentation highlights the dramatic improvement in sleep achievable with an intensive educational, ecological approach incorporating behavioral and sensory interventions by well-trained providers and highly motivated parents. To be effective, this intervention demands commitment to a non-pharmacological approach by the provider and parent and requires confidence that behavioral change is possible. Moreover, ecological 
changes are quick and cost-effective, and parents in our study were very receptive to these environmental changes. The next steps for dissemination of the ATN practice pathway for sleep in children with ASD will need to address local, state, and national barriers to implementation of ecological and behavioral sleep treatment with fidelity. This will require a paradigm shift in the health care arena to mobilize resources to train providers and empower families and communities to implement ecological and behavioral care to improve sleep in children with ASD.

\section{Acknowledgments}

The corresponding author completed a T32 postdoctoral sleep fellowship with Dr. Allan I. Pack at the University of Pennsylvania. The case presentation in this manuscript was a participant in a study funded by the Department of Defense, Office of the Congressionally Directed Medical Research Program, 2013 AR120166.

\section{References}

Papers of particular interest, published recently, have been highlighted as:

- Of importance

1. Gozal D. Sleep-disordered breathing and school performance in children. Pediatrics. 1998; $102(3 \mathrm{Pt}$ 1):616-20. [PubMed: 9738185]

2. Maquet P. The role of sleep in learning and memory. Science. 2001; 294(5544):1048-52. DOI: 10.1126/science.1062856 [PubMed: 11691982]

3. Goodlin-Jones BL, Tang K, Liu J, Anders TF. Sleep patterns in preschool-age children with autism, developmental delay, and typical development. J Am Acad Child Adolesc Psychiatry. 2008; 47(8): 930-8. DOI: 10.1097/CHI.ObO13e3181799f7c [PubMed: 18596550]

4. Cohen, DVF. Handbook of autism and pervasive developmental disorders. 2nd. Toronto: John Wiley \& Sons; 1997.

5•. Mazurek MO, Sohl K. Sleep and behavioral problems in children with autism Spectrum disorder. J Autism Dev Disord. 2016; In this study, sleep disturbances in children with ASD are associated with daytime behavioral dysregulation. Night wakings in particular had the strongest correlation with daytime behavior problems, even after controlling for age and sex. doi: 10.1007/ s10803-016-2723-7

6. DeVincent CJ, Gadow KD, Delosh D, Geller L. Sleep disturbance and its relation to DSM-IV psychiatric symptoms in preschool-age children with pervasive developmental disorder and community controls. J Child Neurol. 2007; 22(2):161-9. DOI: 10.1177/0883073807300310 [PubMed: 17621477]

7. Robinson-Shelton A, Malow BA. Sleep Disturbances in Neurodevelopmental Disorders. Curr Psychiatry Rep. 2016; 18(1):6.doi: 10.1007/s11920-015-0638-1 [PubMed: 26719309]

8. Christensen CLBJ, Van Naarden Braun K, Bilder D, Charles J, Constantino JN, Daniels J, Durkin MS, Fitzgerald RT, Kurzius-Spencer M, Lee L, Pettygrove S, Robinson C, Schulz E, Wells C, Wingate MS, Zahorodny W, Yeargin-Allsopp M. Prevalence and characteristics of autism Spectrum disorder among children aged 8 years - Autism and developmental disabilities monitoring Network, 11 sites, United States. MMWR Surveill Summ. 2012; 65(3):1-23.

9. Parikshak NN, Luo R, Zhang A, Won H, Lowe JK, Chandran V, et al. Integrative functional genomic analyses implicate specific molecular pathways and circuits in autism. Cell. 2013; 155(5):1008-21. DOI: 10.1016/j.cell.2013.10.031 [PubMed: 24267887]

10. Werling DM, Parikshak NN, Geschwind DH. Gene expression in human brain implicates sexually dimorphic pathways in autism spectrum disorders. Nat Commun. 2016; 7:10717.doi: 10.1038/ ncomms10717 [PubMed: 26892004] 
11. Yang Z, Matsumoto A, Nakayama K, Jimbo EF, Kojima K, Nagata K, et al. Circadian-relevant genes are highly polymorphic in autism spectrum disorder patients. Brain and Development. 2016; 38(1):91-9. DOI: 10.1016/j.braindev.2015.04.006 [PubMed: 25957987]

12. Willsey AJ, Sanders SJ, Li M, Dong S, Tebbenkamp AT, Muhle RA, et al. Coexpression networks implicate human midfetal deep cortical projection neurons in the pathogenesis of autism. Cell. 2013; 155(5):997-1007. DOI: 10.1016/j.cell.2013.10.020 [PubMed: 24267886]

13. Wood CL, Warnell F, Johnson M, Hames A, Pearce MS, McConachie H, et al. Evidence for ASD recurrence rates and reproductive stoppage from large UK ASD research family databases. Autism Res. 2015; 8(1):73-81. DOI: 10.1002/aur.1414 [PubMed: 25273900]

14. Risch N, Hoffmann TJ, Anderson M, Croen LA, Grether JK, Windham GC. Familial recurrence of autism spectrum disorder: Evaluating genetic and environmental contributions. Am J Psychiatry. 2014; 171(11):1206-13. 13101359. DOI: 10.1176/appi.ajp.2014 [PubMed: 24969362]

15. Eapen V, Crncec R, Walter A. Clinical outcomes of an early intervention program for preschool children with autism Spectrum disorder in a community group setting. BMC Pediatr. 2013; 13(1): 3.doi: 10.1186/1471-2431-13-3 [PubMed: 23294523]

16. Eapen V, Crncec R, Walter A. Exploring links between genotypes, phenotypes, and clinical predictors of response to early intensive behavioral intervention in autism Spectrum disorder. Front Hum Neurosci. 2013; 7:567.doi: 10.3389/fnhum.2013.00567 [PubMed: 24062668]

17. Kanner L. Problems of nosology and psychodynamics of early infantile autism. Am J Orthop. 1949; 19(3):416-26.

18. Kanner L. Irrelevant and metaphorical language in early infantile autism. Am J Psychiatry. 1946; 103(2):242-6. DOI: 10.1176/ajp.103.2.242 [PubMed: 21001998]

19. Organization WH. International Classification of Diseases (ICD). 2016

20. Lord C, Rutter M, Le Couteur A. Autism diagnostic interview-revised: A revised version of a diagnostic interview for caregivers of individuals with possible pervasive developmental disorders. J Autism Dev Disord. 1994; 24(5):659-85. [PubMed: 7814313]

21. Association AP. Diagnostic and statistical manual of mental disorders. 5th. Arlington: American Psychiatric Publishing; 2013.

22. Owens JA, Mindell JA. Pediatric insomnia. Pediatr Clin N Am. 2011; 58(3):555-69. DOI: 10.1016/j.pcl.2011.03.011

23. Richdale AL, Schreck KA. Sleep problems in autism spectrum disorders: Prevalence, nature, \& possible biopsychosocial aetiologies. Sleep Med Rev. 2009; 13(6):403-11. DOI: 10.1016/j.smrv. 2009.02.003 [PubMed: 19398354]

24. Wiggs L, Stores G. Sleep patterns and sleep disorders in children with autistic spectrum disorders: Insights using parent report and actigraphy. Dev Med Child Neurol. 2004; 46(6):372-80. [PubMed: 15174528]

25. Schreck KA, Mulick JA, Smith AF. Sleep problems as possible predictors of intensified symptoms of autism. Res Dev Disabil. 2004; 25(1):57-66. [PubMed: 14733976]

26. Souders MC, Mason TB, Valladares O, Bucan M, Levy SE, Mandell DS, et al. Sleep behaviors and sleep quality in children with autism spectrum disorders. Sleep. 2009; 32(12):1566-78. [PubMed: 20041592]

27. Owens J. Classification and epidemiology of childhood sleep disorders. Prim Care. 2008; 35(3): 533-546. vii. DOI: 10.1016/j.pop.2008.06.003 [PubMed: 18710669]

28. Malow BA, Crowe C, Henderson L, McGrew SG, Wang L, Song Y, et al. A sleep habits questionnaire for children with autism spectrum disorders. J Child Neurol. 2009; 24(1):19-24. DOI: 10.1177/0883073808321044 [PubMed: 19168814]

29. Meltzer LJ. Brief report: Sleep in parents of children with autism spectrum disorders. J Pediatr Psychol. 2008; 33(4):380-6. DOI: 10.1093/jpepsy/jsn005 [PubMed: 18250091]

30. Elrod MG, Hood BS. Sleep differences among children with autism spectrum disorders and typically developing peers: A meta-analysis. J Dev Behav Pediatr. 2015; 36(3):166-77. DOI: 10.1097/DBP.0000000000000140 [PubMed: 25741949]

31. Bourgeron $\mathrm{T}$. The possible interplay of synaptic and clock genes in autism spectrum disorders. Cold Spring Harb Symp Quant Biol. 2007; 72:645-54. DOI: 10.1101/sqb.2007.72.020 [PubMed: 18419324] 
32. Malow BA, Adkins KW, Reynolds A, Weiss SK, Loh A, Fawkes D, et al. Parent-based sleep education for children with autism spectrum disorders. J Autism Dev Disord. 2014; 44(1):216-28. DOI: 10.1007/s10803-013-1866-z [PubMed: 23754339]

33. Mindell JA, Meltzer LJ. Behavioural sleep disorders in children and adolescents. Ann Acad Med Singap. 2008; 37(8):722-8. [PubMed: 18797569]

34. Meltzer LJ, Johnson C, Crosette J, Ramos M, Mindell JA. Prevalence of diagnosed sleep disorders in pediatric primary care practices. Pediatrics. 2010; 125(6):e1410-8. DOI: 10.1542/peds. 2009-2725 [PubMed: 20457689]

35. Tordjman S, Najjar I, Bellissant E, Anderson GM, Barburoth M, Cohen D, et al. Advances in the research of melatonin in autism spectrum disorders: Literature review and new perspectives. Int $\mathrm{J}$ Mol Sci. 2013; 14(10):20508-42. DOI: 10.3390/ijms141020508 [PubMed: 24129182]

36. AARC-APT (American Association of Respiratory Care-Association of Polysomnography Technologists) clinical practice guideline. Polysomnography Respir Care. 1995; 40(12):1336-43. [PubMed: 10153260]

37. Ornitz EM, Ritvo ER, Brown MB, La Franchi S, Parmelee T, Walter RD. The EEG and rapid eye movements during REM sleep in normal and autistic children. Electroencephalogr Clin Neurophysiol. 1969; 26(2):167-75. [PubMed: 4183370]

38. Tanguay PE, Ornitz EM, Forsythe AB, Ritvo ER. Rapid eye movement (REM) activity in normal and autistic children during REM sleep. J Autism Child Schizophr. 1976; 6(3):275-88. [PubMed: 186448]

39. Diomedi M, Curatolo P, Scalise A, Placidi F, Caretto F, Gigli GL. Sleep abnormalities in mentally retarded autistic subjects: Down's syndrome with mental retardation and normal subjects. Brain and Development. 1999; 21(8):548-53. [PubMed: 10598057]

40. Elia M, Ferri R, Musumeci SA, Del Gracco S, Bottitta M, Scuderi C, et al. Sleep in subjects with autistic disorder: A neurophysiological and psychological study. Brain and Development. 2000; 22(2):88-92. [PubMed: 10722958]

41. Godbout R, Bergeron C, Limoges E, Stip E, Mottron L. A laboratory study of sleep in Asperger's syndrome. Neuroreport. 2000; 11(1):127-30. [PubMed: 10683843]

42. Thirumalai SS, Shubin RA, Robinson R. Rapid eye movement sleep behavior disorder in children with autism. J Child Neurol. 2002; 17(3):173-8. [PubMed: 12026231]

43. Malow BA, Marzec ML, McGrew SG, Wang L, Henderson LM, Stone WL. Characterizing sleep in children with autism spectrum disorders: A multidimensional approach. Sleep. 2006; 29(12):156371. [PubMed: 17252887]

44. Buckley AW, Rodriguez AJ, Jennison K, Buckley J, Thurm A, Sato S, et al. Rapid eye movement sleep percentage in children with autism compared with children with developmental delay and typical development. Arch Pediatr Adolesc Med. 2010; 164(11):1032-7. DOI: 10.1001/ archpediatrics.2010.202 [PubMed: 21041596]

45. Wimpory D, Nicholas B, Nash S. Social timing, clock genes and autism: A new hypothesis. J Intellect Disabil Res. 2002; 46(Pt 4):352-8. [PubMed: 12000587]

46. Tordjman S, Anderson GM, Pichard N, Charbuy H, Touitou Y. Nocturnal excretion of 6sulphatoxymelatonin in children and adolescents with autistic disorder. Biol Psychiatry. 2005; 57(2):134-8. DOI: 10.1016/j.biopsych.2004.11.003 [PubMed: 15652871]

47. Tordjman S, Davlantis KS, Georgieff N, Geoffray MM, Speranza M, Anderson GM, et al. Autism as a disorder of biological and behavioral rhythms: Toward new therapeutic perspectives. Front Pediatr. 2015; 3:1.doi: 10.3389/fped.2015.00001 [PubMed: 25756039]

48. Botbol M, Cabon P, Kermarrec S, Tordjman S. Biological and psychological rhythms: An integrative approach to rhythm disturbances in autistic disorder. J Physiol Paris. 2013; 107(4):298309. DOI: 10.1016/j.jphysparis.2013.03.009 [PubMed: 23542543]

49. Travnickova-Bendova Z, Cermakian N, Reppert SM, Sassone-Corsi P. Bimodal regulation of mPeriod promoters by CREB-dependent signaling and CLOCK/BMAL1 activity. Proc Natl Acad Sci U S A. 2002; 99(11):7728-33. DOI: 10.1073/pnas.102075599 [PubMed: 12032351]

50. Etchegaray JP, Lee C, Wade PA, Reppert SM. Rhythmic histone acetylation underlies transcription in the mammalian circadian clock. Nature. 2003; 421(6919):177-82. DOI: 10.1038/nature01314 [PubMed: 12483227] 
51. Sasaki M, Yoshitane H, Du NH, Okano T, Fukada Y. Preferential inhibition of BMAL2-CLOCK activity by PER2 reemphasizes its negative role and a positive role of BMAL2 in the circadian transcription. J Biol Chem. 2009; 284(37):25149-59. DOI: 10.1074/jbc.M109.040758 [PubMed: 19605937]

52. Barnes JW, Tischkau SA, Barnes JA, Mitchell JW, Burgoon PW, Hickok JR, et al. Requirement of mammalian Timeless for circadian rhythmicity. Science. 2003; 302(5644):439-42. DOI: 10.1126/ science.1086593 [PubMed: 14564007]

53. Leroy C, Landais E, Briault S, David A, Tassy O, Gruchy N, et al. The 2q37-deletion syndrome: An update of the clinical spectrum including overweight, brachydactyly and behavioural features in 14 new patients. Eur J Hum Genet. 2013; 21(6):602-12. DOI: 10.1038/ejhg.2012.230 [PubMed: 23073310]

54. Nicholas B, Rudrasingham V, Nash S, Kirov G, Owen MJ, Wimpory DC. Association of Per1 and Npas2 with autistic disorder: Support for the clock genes/social timing hypothesis. Mol Psychiatry. 2007; 12(6):581-92. DOI: 10.1038/sj.mp.4001953 [PubMed: 17264841]

55•. Veatch OJ, Keenan BT, Gehrman PR, Malow BA, Pack AI. Pleiotropic genetic effects influencing sleep and neurological disorders. Lancet Neurol. 2017; 16(2):158-70. A greater understanding of pleiotropic roles of genes influencing both sleep and neurological disorders could lead to new treatment strategies. DOI: 10.1016/S1474-4422(16)30339-8 [PubMed: 28102151]

56. Ritvo ERRR, Yuliwer A, Brothers A, Freeman BJ, Plotkin S. Elevated daytime melatonin concentration in autism. Eur Child Adolesc Psychiatry. 1993; 2:75-8.

57. Nir I, Meir D, Zilber N, Knobler H, Hadjez J, Lerner Y. Brief report: Circadian melatonin, thyroidstimulating hormone, prolactin, and cortisol levels in serum of young adults with autism. J Autism Dev Disord. 1995; 25(6):641-54. [PubMed: 8720032]

58. Kulman G, Lissoni P, Rovelli F, Roselli MG, Brivio F, Sequeri P. Evidence of pineal endocrine hypofunction in autistic children. Neuro Endocrinol Lett. 2000; 21(1):31-4. [PubMed: 11455326]

59. Melke J, Goubran Botros H, Chaste P, Betancur C, Nygren G, Anckarsater H, et al. Abnormal melatonin synthesis in autism spectrum disorders. Mol Psychiatry. 2008; 13(1):90-8. DOI: 10.1038/sj.mp.4002016 [PubMed: 17505466]

60. Mulder EJ, Anderson GM, Kemperman RF, Oosterloo-Duinkerken A, Minderaa RB, Kema IP. Urinary excretion of 5-hydroxyindoleacetic acid, serotonin and 6-sulphatoxymelatonin in normoserotonemic and hyperserotonemic autistic individuals. Neuropsychobiology. 2010; 61(1): 27-32. DOI: 10.1159/000258640 [PubMed: 19923863]

61. Veatch OJ, Veenstra-Vanderweele J, Potter M, Pericak-Vance MA, Haines JL. Genetically meaningful phenotypic subgroups in autism spectrum disorders. Genes Brain Behav. 2014; 13(3): 276-85. DOI: 10.1111/gbb.12117 [PubMed: 24373520]

62. Chaste P, Clement N, Mercati O, Guillaume JL, Delorme R, Botros HG, et al. Identification of pathway-biased and deleterious melatonin receptor mutants in autism spectrum disorders and in the general population. PLoS One. 2010; 5(7):e11495.doi: 10.1371/journal.pone.0011495 [PubMed: 20657642]

63. Jonsson L, Ljunggren E, Bremer A, Pedersen C, Landen M, Thuresson K, et al. Mutation screening of melatonin-related genes in patients with autism spectrum disorders. BMC Med Genet. 2010; 3:10.doi: 10.1186/1755-8794-3-10

64. Gupta R, Hutchins J. Melatonin: A panacea for desperate parents? (hype or truth). Arch Dis Child. 2005; 90(9):986-7. DOI: 10.1136/adc.2005.075218

65. Andersen IM, Kaczmarska J, McGrew SG, Malow BA. Melatonin for insomnia in children with autism spectrum disorders. J Child Neurol. 2008; 23(5):482-5. DOI: 10.1177/0883073807309783 [PubMed: 18182647]

66. Galli-Carminati G, Deriaz N, Bertschy G. Melatonin in treatment of chronic sleep disorders in adults with autism: A retrospective study. Swiss Med Wkly. 2009; 139(19-20):293-6. [PubMed: 19452292]

67. Jan JE, Espezel H, Appleton RE. The treatment of sleep disorders with melatonin. Dev Med Child Neurol. 1994; 36(2):97-107. [PubMed: 8132132]

Curr Psychiatry Rep. Author manuscript; available in PMC 2018 June 01. 
68. Ishizaki A, Sugama M, Takeuchi N. Usefulness of melatonin for developmental sleep and emotional/behavior disorders-studies of melatonin trial on 50 patients with developmental disorders. No To Hattatsu. 1999; 31(5):428-37. [PubMed: 10487068]

69. Paavonen EJ, Nieminen-von Wendt T, Vanhala R, Aronen ET, von Wendt L. Effectiveness of melatonin in the treatment of sleep disturbances in children with Asperger disorder. J Child Adolesc Psychopharmacol. 2003; 13(1):83-95. DOI: 10.1089/104454603321666225 [PubMed: 12804129]

70. Giannotti F, Cortesi F, Cerquiglini A, Bernabei P. An open-label study of controlled-release melatonin in treatment of sleep disorders in children with autism. J Autism Dev Disord. 2006; 36(6):741-52. DOI: 10.1007/s10803-006-0116-z [PubMed: 16897403]

71. De Leersnyder H, Zisapel N, Laudon M. Prolonged-release melatonin for children with neurodevelopmental disorders. Pediatr Neurol. 2011; 45(1):23-6. DOI: 10.1016/j.pediatrneurol. 2011.02.001 [PubMed: 21723455]

72. Malow BAAK, McGrew S, Wang L, Goldman S, Fawkes D, Burnette C. Melatonin for sleep in children with autism: A controlled trial examining dose, tolerability and outcomes. J Autism Dev Disord. 2011; 42

73. McArthur AJ, Budden SS. Sleep dysfunction in Rett syndrome: A trial of exogenous melatonin treatment. Dev Med Child Neurol. 1998; 40(3):186-92. [PubMed: 9566656]

74. Garstang J, Wallis M. Randomized controlled trial of melatonin for children with autistic spectrum disorders and sleep problems. Child Care Health Dev. 2006; 32(5):585-9. DOI: 10.1111/j. 1365-2214.2006.00616.x [PubMed: 16919138]

75. Wasdell MB, Jan JE, Bomben MM, Freeman RD, Rietveld WJ, Tai J, et al. A randomized, placebocontrolled trial of controlled release melatonin treatment of delayed sleep phase syndrome and impaired sleep maintenance in children with neurodevelopmental disabilities. J Pineal Res. 2008; 44(1):57-64. DOI: 10.1111/j.1600-079X.2007.00528.x [PubMed: 18078449]

76. Wirojanan J, Jacquemont S, Diaz R, Bacalman S, Anders TF, Hagerman RJ, et al. The efficacy of melatonin for sleep problems in children with autism, fragile $\mathrm{X}$ syndrome, or autism and fragile $\mathrm{X}$ syndrome. J Clin Sleep Med. 2009; 5(2):145-50. [PubMed: 19968048]

77. Wright B, Sims D, Smart S, Alwazeer A, Alderson-Day B, Allgar V, et al. Melatonin versus placebo in children with autism spectrum conditions and severe sleep problems not amenable to behaviour management strategies: A randomised controlled crossover trial. J Autism Dev Disord. 2011; 41(2):175-84. DOI: 10.1007/s10803-010-1036-5 [PubMed: 20535539]

78. Cortesi F, Giannotti F, Sebastiani T, Panunzi S, Valente D. Controlled-release melatonin, singly and combined with cognitive behavioural therapy, for persistent insomnia in children with autism spectrum disorders: A randomized placebo-controlled trial. J Sleep Res. 2012; 21(6):700-9. DOI: 10.1111/j.1365-2869.2012.01021.x [PubMed: 22616853]

79. Gringras P, Gamble C, Jones AP, Wiggs L, Williamson PR, Sutcliffe A, et al. Melatonin for sleep problems in children with neurodevelopmental disorders: Randomised double masked placebo controlled trial. BMJ. 2012; 345:e6664.doi: 10.1136/bmj.e6664 [PubMed: 23129488]

80. Goldman SE, Adkins KW, Calcutt MW, Carter MD, Goodpaster RL, Wang L, et al. Melatonin in children with autism spectrum disorders: Endogenous and pharmacokinetic profiles in relation to sleep. J Autism Dev Disord. 2014; 44(10):2525-35. DOI: 10.1007/s10803-014-2123-9 [PubMed: 24752680]

81. Hall M, Buysse DJ, Dew MA, Prigerson HG, Kupfer DJ, Reynolds CF 3rd. Intrusive thoughts and avoidance behaviors are associated with sleep disturbances in bereavement-related depression. Depress Anxiety. 1997; 6(3):106-12. [PubMed: 9442984]

82. Levenson JC, Kay DB, Buysse DJ. The pathophysiology of insomnia. Chest. 2015; 147(4):117992. DOI: 10.1378/chest.14-1617 [PubMed: 25846534]

83. Perlis ML, Smith MT, Orff H, Enright T, Nowakowski S, Jungquist C, et al. The effects of modafinil and cognitive behavior therapy on sleep continuity in patients with primary insomnia. Sleep. 2004; 27(4):715-25. [PubMed: 15283007]

84. Bonnet MH, Arand DL. Hyperarousal and insomnia: State of the science. Sleep Med Rev. 2010; 14(1):9-15. DOI: 10.1016/j.smrv.2009.05.002 [PubMed: 19640748] 
85. Feige B, Baglioni C, Spiegelhalder K, Hirscher V, Nissen C, Riemann D. The microstructure of sleep in primary insomnia: An overview and extension. Int J Psychophysiol. 2013; 89(2):171-80. DOI: 10.1016/j.ijpsycho.2013.04.002 [PubMed: 23583625]

86. Healey ES, Kales A, Monroe LJ, Bixler EO, Chamberlin K, Soldatos CR. Onset of insomnia: Role of life-stress events. Psychosom Med. 1981; 43(5):439-51. [PubMed: 7313035]

87. Morin CM, Rodrigue S, Ivers H. Role of stress, arousal, and coping skills in primary insomnia. Psychosom Med. 2003; 65(2):259-67. [PubMed: 12651993]

88. Hutt C, Hutt SJ, Lee D, Ounsted C. Arousal and childhood autism. Nature. 1964; 204:908-9. [PubMed: 14235732]

89. Dawson G, Finley C, Phillips S, Galpert L, Lewy A. Reduced P3 amplitude of the event-related brain potential: Its relationship to language ability in autism. J Autism Dev Disord. 1988; 18(4): 493-504. [PubMed: 3215878]

90. van Engeland $\mathrm{H}$. The electrodermal orienting response to auditive stimuli in autistic children, normal children, mentally retarded children, and child psychiatric patients. J Autism Dev Disord. 1984; 14(3):261-79. [PubMed: 6237097]

91. Barry RJ, James AL. Coding of stimulus parameters in autistic, retarded, and normal children: Evidence for a two-factor theory of autism. Int J Psychophysiol. 1988; 6(2):139-49. [PubMed: 3397316]

92. Palkovitz RJ, Wiesenfeld AR. Differential autonomic responses of autistic and normal children. J Autism Dev Disord. 1980; 10(3):347-60. [PubMed: 6927661]

93. Hirstein W, Iversen P, Ramachandran VS. Autonomic responses of autistic children to people and objects. Proc Biol Sci. 2001; 268(1479):1883-8. [PubMed: 11564343]

94. Ming X, Julu PO, Brimacombe M, Connor S, Daniels ML. Reduced cardiac parasympathetic activity in children with autism. Brain and Development. 2005; 27(7):509-16. [PubMed: 16198209]

95. Reynolds S, Lane SJ, Thacker L. Sensory processing, physiological stress, and sleep behaviors in children with and without autism spectrum disorders. Occupational Therapy Journal of Research. 2012; 32(1)doi: 10.3928/15394492-20110513-02

96. McIntosh, DN., Miller, LJ., Shyu, V. Development and validation of the short sensory profile. In: Dunn, W., editor. Sensory profile manual. San Antonio: Psychological Corporation; 1999. p. 59-73.

97. McIntosh DN, Miller LJ, Shyu V, Hagerman RJ. Sensory-modulation disruption, electrodermal responses, and functional behaviors. Developmental Medicine \& Child Neurology. 1999; 41(9): 608-15. DOI: 10.1111/j.1469-8749.1999.tb00664.x [PubMed: 10503919]

98. Dunn, W. The sensory profile. San Antonio: The Psychological Corporation; 1999.

99•. Mazurek MO, Petroski GF. Sleep problems in children with autism spectrum disorder: Examining the contributions of sensory over-responsivity and anxiety. Sleep Med. 2015; 16(2):270-9. This study included 1, 347 children with ASD and revealed strong relationships among anxiety, sensory over-responsivity, and sleep disturbance, due to a state of hyperarousal. DOI: 10.1016/ j.sleep.2014.11.006 [PubMed: 25600781]

100•. Hollway JA, Aman MG, Butter E. Correlates and risk markers for sleep disturbance in participants of the autism treatment Network. J Autism Dev Disord. 2013; 43(12):2830-43. This study found that GI disturbance, autism symptom severity, anxiety, and sensory sensitivities are correlated with sleep disturbances. IQ predicted sleep disturbances, suggesting that children with Asperger's Disorder are vulnerable to sleep disturbances. DOI: 10.1007/s 10803-013-1830-y [PubMed: 23624832]

101. White SW, Lerner MD, McLeod BD, Wood JJ, Ginsburg GS, Kerns C, et al. Anxiety in youth with and without autism spectrum disorder: Examination of factorial equivalence. Behav Ther. 2015; 46(1):40-53. DOI: 10.1016/j.beth.2014.05.005 [PubMed: 25526834]

102. Kerns CM, Maddox BB, Kendall PC, Rump K, Berry L, Schultz RT, et al. Brief measures of anxiety in non-treatment-seeking youth with autism spectrum disorder. Autism. 2015; 19(8):96979. DOI: 10.1177/1362361314558465 [PubMed: 25633222] 
103. Kerns CM, Kendall PC, Berry L, Souders MC, Franklin ME, Schultz RT, et al. Traditional and atypical presentations of anxiety in youth with autism spectrum disorder. J Autism Dev Disord. 2014; 44(11):2851-61. DOI: 10.1007/s10803-014-2141-7 [PubMed: 24902932]

104. Yerys BE, Wallace GL, Sokoloff JL, Shook DA, James JD, Kenworthy L. Attention deficit/ hyperactivity disorder symptoms moderate cognition and behavior in children with autism spectrum disorders. Autism Res. 2009; 2(6):322-33. DOI: 10.1002/aur.103 [PubMed: 19998356]

105. Aston-Jones G, Rajkowski J, Cohen J. Role of locus coeruleus in attention and behavioral flexibility. Biol Psychiatry. 1999; 46(9):1309-20. [PubMed: 10560036]

106. Aston-Jones G, Cohen JD. An integrative theory of locus coeruleus-norepinephrine function: Adaptive gain and optimal performance. Annu Rev Neurosci. 2005; 28:403-50. [PubMed: 16022602]

107. Panju S, Brian J, Dupuis A, Anagnostou E, Kushki A. Atypical sympathetic arousal in children with autism spectrum disorder and its association with anxiety symptomatology. Mol Autism. 2015; 6:64.doi: 10.1186/s13229-015-0057-5 [PubMed: 26693000]

108. Brennan AR, Arnsten AF. Neuronal mechanisms underlying attention deficit hyperactivity disorder: The influence of arousal on prefrontal cortical function. Ann N YAcad Sci. 2008; 1129:236-45.

109. Swanson LW. The locus coeruleus: A cytoarchitectonic, Golgi and immunohistochemical study in the albino rat. Brain Res. 1976; 110(1):39-56. [PubMed: 776360]

110. Swanson LW, Hartman BK. The central adrenergic system. An immunofluorescence study of the location of cell bodies and their efferent connections in the rat utilizing dopamine-betahydroxylase as a marker. J Comp Neurol. 1975; 163(4):467-505. [PubMed: 1100685]

111. Aston-Jones G, Bloom FE. Activity of norepinephrine-containing locus coeruleus neurons in behaving rats anticipates fluctuations in the sleep-waking cycle. J Neurosci. 1981; 1(8):876-86. [PubMed: 7346592]

112. Aston-Jones G, Bloom FE. Norepinephrine-containing locus coeruleus neurons in behaving rats exhibit pronounced responses to non-noxious environmental stimuli. J Neurosci. 1981; 1(8):887900. [PubMed: 7346593]

113. Valentino RJ, Van Bockstaele E. Convergent regulation of locus coeruleus activity as an adaptive response to stress. Eur J Pharmacol. 2008; 583(2-3):194-203. [PubMed: 18255055]

114. Berridge CW, Schmeichel BE, Espana RA. Noradrenergic modulation of wakefulness/arousal. Sleep Med Rev. 2012; 16(2):187-97. DOI: 10.1016/j.smrv.2011.12.003 [PubMed: 22296742]

115. Renton GH, Weil-Malherbe H. Adrenaline and noradrenaline in human plasma during natural sleep. J Physiol. 1956; 131(1):170-5. [PubMed: 13296054]

116. Spielman AJ, Caruso LS, Glovinsky PB. A behavioral perspective on insomnia treatment. Psychiatr Clin North Am. 1987; 10(4):541-53. [PubMed: 3332317]

117•. Malow BA, Byars K, Johnson K, Weiss S, Bernal P, Goldman SE, et al. A practice pathway for the identification, evaluation, and management of insomnia in children and adolescents with autism spectrum disorders. Pediatrics. 2012; 130(Suppl 2):S106-24. This is the first consensus paper to provide a practical algorithm supporting decision-making for providers caring for children with ASD and insomnia. DOI: 10.1542/peds.2012-0900I [PubMed: 23118242]

118. Linehan, MM. Skills training manual for treating borderline personality disorder. The Guilford Press; 1993.

119. Kid N. Yoga for Kids. 2016

120. Silva LM, Cignolini A. A medical qigong methodology for early intervention in autism spectrum disorder: A case series. Am J Chin Med. 2005; 33(2):315-27. DOI: 10.1142/ S0192415X05002837 [PubMed: 15974490]

121. Silva LM, Cignolini A, Warren R, Budden S, Skowron-Gooch A. Improvement in sensory impairment and social interaction in young children with autism following treatment with an original qigong massage methodology. Am J Chin Med. 2007; 35(3):393-406. DOI: 10.1142/ S0192415X07004916 [PubMed: 17597498]

122. Silva LM, Schalock M, Ayres R, Bunse C, Budden S. Qigong massage treatment for sensory and self-regulation problems in young children with autism: A randomized controlled trial. Am J Occup Ther. 2009; 63(4):423-32. [PubMed: 19708471] 
123. Silva LM, Schalock M, Gabrielsen K. Early intervention for autism with a parent-delivered qigong massage program: A randomized controlled trial. Am J Occup Ther. 2011; 65(5):550-9. [PubMed: 22026323]

124. Hanh, TN. Mindful movements: Ten exercises for well-being. Berkley: Parralax Press; 2008.

125. Dadoly, A. Two techniques for reducing stress. 2011. www.health.harvard.edu/blog/twotechniques-for-reducing-stress-201104092235

126. Owens JA, Spirito A, McGuinn M. The Children's Sleep Habits Questionnaire (CSHQ): Psychometric properties of a survey Instrument for school-aged children. Sleep. 2000; 23(8): 1043-51. [PubMed: 11145319]

127. Research Units on Pediatric Psychopharmacology Anxiety Study Group. The pediatric anxiety rating scale (PARS): Development and psychometric properties. J Am Acad Child Adolesc Psychiatry. 2002; 41:1061-1069. [PubMed: 12218427]

128. Storch EA, Wood JJ, Ehrenreich-May J, Jones AM, Park JM, Lewin AB, et al. Convergent and discriminant validity and reliability of the pediatric anxiety rating scale in youth with autism spectrum disorders. J Autism Dev Disord. 2012; 42(11):2374-82. DOI: 10.1007/ s10803-012-1489-9 [PubMed: 22395820]

129. Kerns CM, Renno P, Kendall PC, Wood JJ, Storch EA. Anxiety Disorders Interview Schedule Autism Addendum: Reliability and Validity in Children with Autism Spectrum Disorder. Journal of Child Clinical and Adolescent Psychology. 2017

130. Kerns CM, Wood JJ, Kendall PC, Renno P, Crawford EA, Mercado RJ, et al. The Treatment of Anxiety in Autism Spectrum Disorder (TAASD) study: rationale, design and methods. Journal of Child and Family Studies. 2016; 25(6):1889-902. [PubMed: 28747814]

131. Storch EA, Arnold EB, Lewin AB, Nadeau JM, Jones AM, De Nadai AS, et al. The effect of cognitive-behavioral therapy versus treatment as usual for anxiety in children with autism spectrum disorders: A randomized, controlled trial. J Am Acad Child Adolesc Psychiatry. 2013; 52(2):132-142 e2. DOI: 10.1016/j.jaac.2012.11.007 [PubMed: 23357440]

132. Birmaher B, Brent DA, Chiappetta L, Bridge J, Monga S, Baugher M. Psychometric properties of the screen for child anxiety related emotional disorders (SCARED): A replication study. J Am Acad Child Adolesc Psychiatry. 1999; 38(10):1230-6. DOI: 10.1097/00004583-199910000-00011 [PubMed: 10517055]

133. Birmaher B, Khetarpal S, Brent D, Cully M, Balach L, Kaufman J, et al. The screen for child anxiety related emotional disorders (SCARED): Scale construction and psychometric characteristics. J Am Acad Child Adolesc Psychiatry. 1997; 36(4):545-53. DOI: 10.1097/00004583-199704000-00018 [PubMed: 9100430]

134. Reaven JA, Blakeley-Smith A, Nichols S, Dasari M, Flanigan E, Hepburn S. Cognitive-behavioral group treatment for anxiety symptoms in children with high-functioning autism spectrum disorders a pilot study. Focus on Autism and Other Developmental Disabilities. 2009; 24(1):2737. 


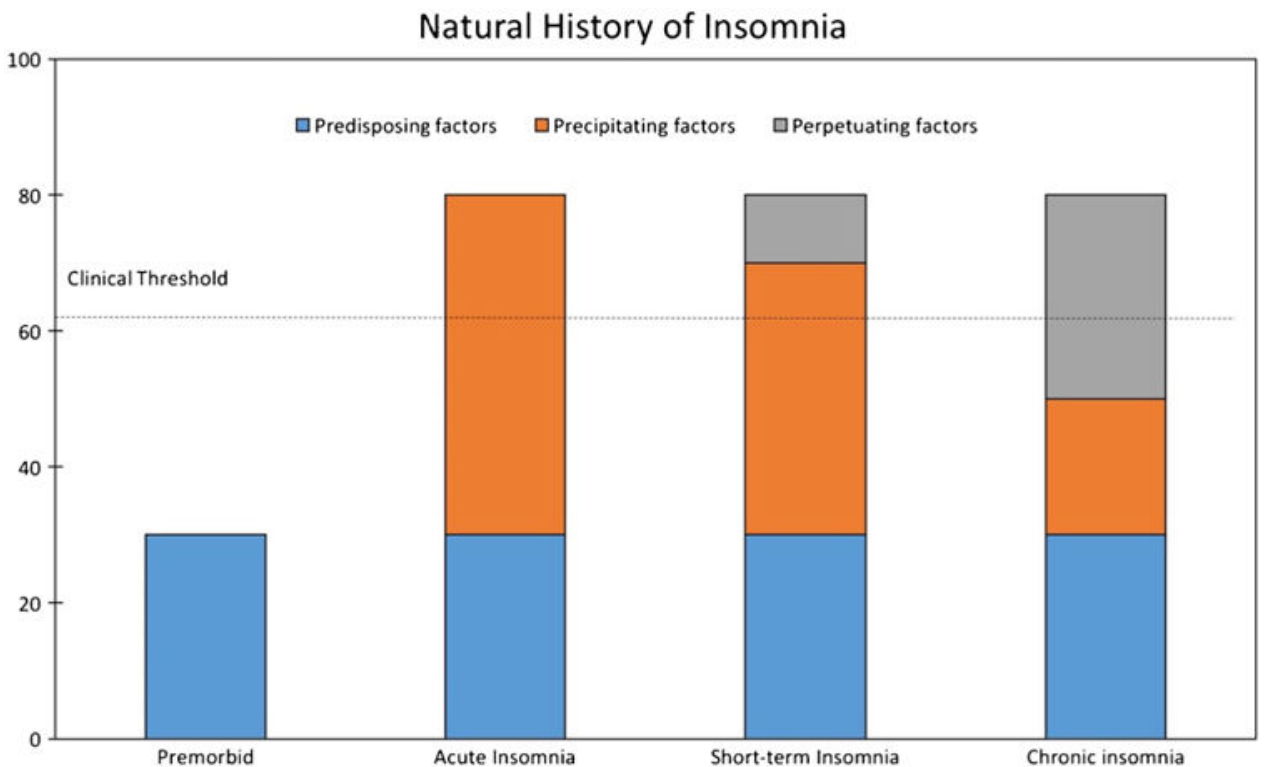

Fig. 1.

Spielman's model of insomnia. From Spielman AJ, Caruso LS, Glovinsky PB. A behavioral perspective on insomnia treatment. Psychiatr Clin North Am. 1987;10(4):541-53 
Baseline

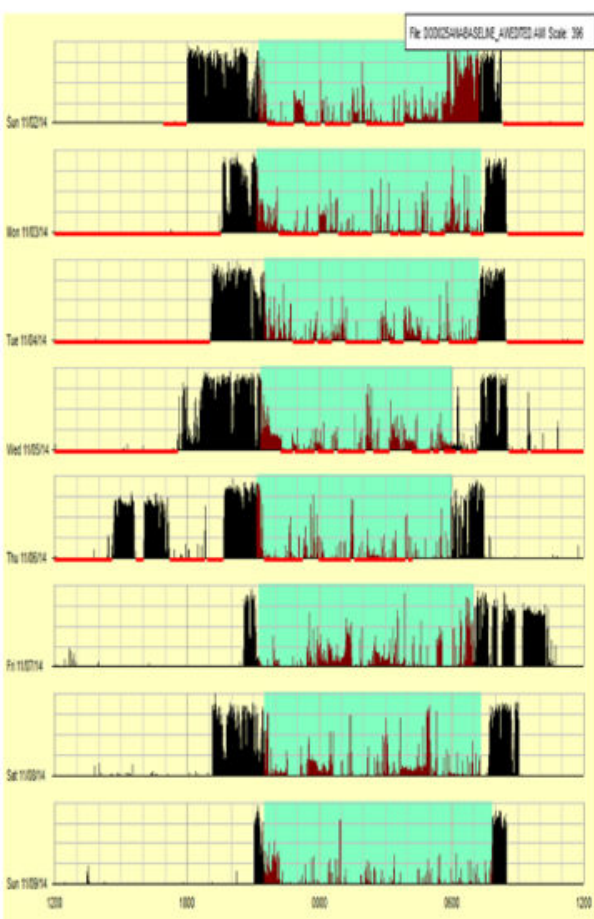

Week 8

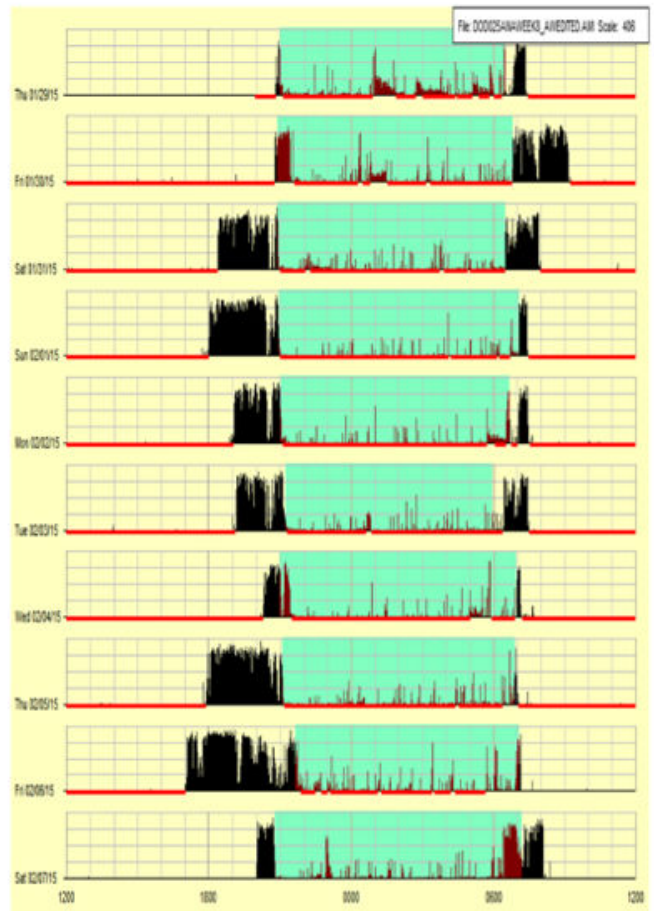

Fig. 2. Actigraphy data from baseline and week 8 for participant 


\section{Table 1}

\section{Practice pathway 10 step approach}

1. Screen all children with ASD for insomnia with sleep questionnaire annually.

2. Identify any parent or child sleep concerns and discuss.

3. Screen for medical conditions that may be contributing to insomnia and refer to appropriate sub-specialist (Tables 2 and 3).

4. Treat any medical conditions significantly affecting sleep before continuing with the practice pathway.

5. Determine the willingness and capacity of the family to implement a sleep intervention.

6. The first-line approach is parent education about environmental modification, positive bedtime routines, and behavioral strategies.

7. Introduce the ATN Sleep Tool Kit and educational materials with visual schedule.

8. If the family is unable or unwilling to follow environmental and behavioral strategies consider consultation to a sleep specialist.

9. Pharmacological interventions may be considered, start with melatonin.

10. Timely follow-up in 2-4 weeks for all interventions Annual reassessment for all children with ASD 
Table 2

\section{Medical conditions contributing to sleep problems}

\begin{tabular}{l}
\hline Gastrointestinal disorders \\
Reflux \\
Constipation \\
Pain \\
Respiratory disorders \\
Sleep-disordered breathing \\
Allergies \\
Asthma \\
Neurological disorders \\
Epilepsy/seizures \\
Restless leg syndrome/abnormal movements \\
Skin and integumentary disorders \\
Dental issues \\
Eczema/itching \\
Sensitivity to textures/light/sound \\
Nutrition \\
Hunger \\
Iron deficiency \\
"Growing pains" \\
\hline
\end{tabular}


Table 3

Obstructive sleep apnea (OSA) signs/symptoms and physical risk factors

OSA signs and symptoms:
Snoring/loud breathing
Snorting/gasping for breath
Periods of apnea (child stops breathing for a moment)
Unrefreshing sleep/daytime sleepiness
Physical risk factors:
Obesity
Large tonsils and/or adenoids
Hypotonia
Micrognathia (small chin)
Palatal defects




\section{Table 4}

Tim's sleep and anxiety data

\begin{tabular}{|c|c|c|c|}
\hline Measure & Baseline & Week 8 & Change \\
\hline \multicolumn{4}{|l|}{ Actigraph data } \\
\hline Starting time & 21:19:59 & 21:03:59 & $-00: 16: 00$ \\
\hline Ending time & $7: 00: 14$ & $6: 45: 37$ & $-0: 14: 37$ \\
\hline Duration & 581.13 & 582 & +0.87 \\
\hline Activity mean & 34.07 & 17.95 & -16.12 \\
\hline Wake minutes & 205.5 & 127.2 & -78.3 \\
\hline Sleep minutes & 375.63 & 455.4 & +79.77 \\
\hline$\%$ Sleep & 64.77 & 78.82 & +14.05 \\
\hline Sleep efficiency & 74.3 & 82.5 & +8.2 \\
\hline Sleep latency & 37.75 & 13.22 & -24.53 \\
\hline \multicolumn{4}{|l|}{ CSHQ sleep behaviors } \\
\hline Bedtime resistance & 15 & 8 & -7 \\
\hline Sleep onset delay & 2 & 1 & -1 \\
\hline Sleep duration & 6 & 4 & -2 \\
\hline Sleep anxiety & 10 & 6 & -4 \\
\hline Night wakings & 6 & 4 & -2 \\
\hline Parasomnias & 10 & 7 & -3 \\
\hline Sleep disordered breathing & 4 & 3 & -1 \\
\hline Daytime sleepiness & 10 & 12 & +2 \\
\hline Total score & 57 & 41 & -16 \\
\hline \multicolumn{4}{|l|}{ Anxiety } \\
\hline PARS & 14 & 10 & -4 \\
\hline SCARED & 23 & 15 & -8 \\
\hline
\end{tabular}

Curr Psychiatry Rep. Author manuscript; available in PMC 2018 June 01. 


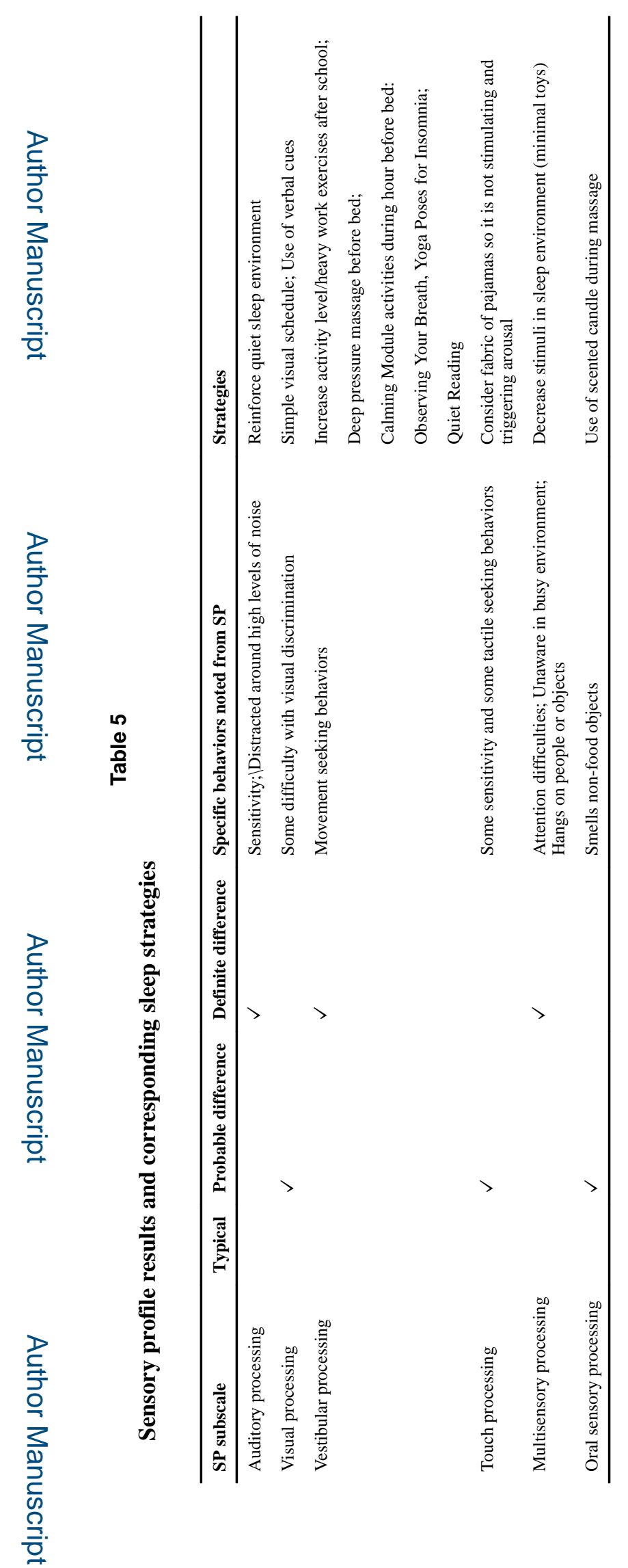

Curr Psychiatry Rep. Author manuscript; available in PMC 2018 June 01. 
Table 6

Standard care plus TAB for Tim

\begin{tabular}{|c|c|}
\hline & Interventions: \\
\hline \multirow[t]{6}{*}{ Ecological } & Remove toys and TV from room \\
\hline & Cool, dark environment \\
\hline & Transition to own bedroom \\
\hline & Nightlight \\
\hline & Pillow with mother's PJs and perfume \\
\hline & Vanilla candle \\
\hline \multirow[t]{2}{*}{ Positive routines } & Visual schedule \\
\hline & Quiet reading \\
\hline \multirow[t]{4}{*}{ Calming activities } & Massage \\
\hline & Yoga poses \\
\hline & Deep breathing \\
\hline & $20 \mathrm{~min}$ exercise during the day \\
\hline \multirow[t]{2}{*}{ Stimulus control } & Faded bedtime protocol (consolidate sleep) \\
\hline & ATN bedtime pass \\
\hline
\end{tabular}

